OPEN ACCESS

Edited by:

Francois Galgani, Institut Français de Recherche pour l'Exploitation de la Mer (IFREMER),

France

Reviewed by:

Christian Joshua Sanders, Southern Cross University, Australia Jianhui Tang

Yantai Institute of Coastal Zone Research (CAS), China

*Correspondence: Karin F. Kvale kkvale@geomar.de

Specialty section:

This article was submitted to Marine Pollution a section of the journa Frontiers in Marine Science

Received: 26 August 2019 Accepted: 16 December 2019

Published: 21 January 2020

Citation: Kvale KF, Friederike Prowe $A E$ and Oschlies A (2020) A Critical Examination of the Role of Marine Snow and Zooplankton Fecal Pellets

in Removing Ocean Surface

Microplastic. Front. Mar. Sci. 6:808.

doi: 10.3389/fmars.2019.00808

\section{A Critical Examination of the Role of Marine Snow and Zooplankton Fecal Pellets in Removing Ocean Surface Microplastic}

\author{
Karin F. Kvale*, A. E. Friederike Prowe and Andreas Oschlies \\ GEOMAR Helmholtz Centre for Ocean Research, Kiel, Germany
}

Numerical simulations and emissions estimates of plastic in and to the ocean consistently over-predict the surface inventory, particularly in the case of microplastic (MP), i.e., fragments less than $5 \mathrm{~mm}$ in length. Sequestration in the sediments has been both predicted and, to a limited extent, observed. It has been hypothesized that biology may be exporting a significant fraction of surface MP by way of marine snow aggregation and zooplankton fecal pellets. We apply previously published data on MP concentrations in the surface ocean to an earth system model of intermediate complexity to produce a first estimate of the potential global sequestration of MP by marine aggregates, including fecal pellets. We find a MP seafloor export potential of between 7.3E3 and 4.2E5 metric tons per year, or about $0.06-8.8 \%$ of estimated total annual plastic ocean pollution rates. We find that presently, aggregates alone would have the potential to remove most existing surface ocean MP to the seafloor within less than 2 years if pollution ceases. However, the observed accumulation of MP in the surface ocean, despite this high potential rate of removal, suggests that detrital export is an ineffective pathway for permanent MP removal. We theorize a prominent role of MP biological fouling and de-fouling in the rapid recycling of aggregate-associated MP in the upper ocean. We also present an estimate of how the potential detrital MP sink might change into the future, as climate change (and projected increasing MP pollution) alters the marine habitat. The polar regions, and the Arctic in particular, are projected to experience increasing removal rates as export production increases faster than MP pollution. Northern hemisphere subtropical gyres are projected to experience slowing removal rates as stratification and warming decrease export production, and MP pollution increases. However, significant uncertainty accompanies these results.

Keywords: microplastic, marine aggregates, climate change, pollution, zooplankton, marine snow, budget

\section{INTRODUCTION}

While the scientific community has been aware of the presence of plastic pollution in the ocean since at least the 1970s (Wong et al., 1974; Day and Shaw, 1987) significant momentum into cataloging its characteristics, spatial distribution and temporal trends is more recent (e.g., Thompson et al., 2004; Law et al., 2010, 2014; Cózar et al., 2014, 2017; Eriksen et al., 2014; Enders et al., 2015; Isobe et al., 2015). Urgency to quantify the inventory mounts as the negative ecological 
effects of plastic pollution become increasingly apparent (see the recent review by Galloway et al., 2017). Particle tracking ocean models are useful in this respect, and have been used to predict potential locations of plastic accumulation in the ocean surface and along coastlines (van Sebille et al., 2012) and to estimate global inventory and concentrations (Eriksen et al., 2014; van Sebille et al., 2015, and references therein); see Hardesty et al. (2017) for a review. A notable outcome of these efforts is an apparent and significant quantity of missing plastic- that is, plastic that is predicted to exist in the ocean based on available estimates of plastic pollution (e.g., Jambeck et al., 2015) and what is known about ocean surface currents, but that is not found in the surface layer by sampling nets (Cózar et al., 2014; Eriksen et al., 2014).

While the sources of plastic are thought to be fairly wellconstrained, the sinks of plastic are less so. Plastics are known to degrade by physical, photochemical, and biological processes (see Galloway et al., 2017, for a review). More than $80 \%$ of the missing plastic qualifies as microplastic (MP, or plastics between 0.1 and $5 \mathrm{~mm}$ in length), and smaller (Cózar et al., 2014). These tiny particles might have been missed by historical sampling and are thus under-reported, or they might sink to the sediments (Woodall et al., 2014) or into deeper ocean water masses (Peng et al., 2018; Choy et al., 2019). Also, not all plastics are transported uniformly in the real ocean; e.g., the most significant concentrations of microfibers occurring far away from the most significant concentrations of other plastics in a recent survey of the Arctic (Cózar et al., 2017). MP particle modeling suggests MP might oscillate within the upper 100 $\mathrm{m}$ as a product of biofouling/de-fouling (Kooi et al., 2016). Microplastic aggregation in marine snows (e.g., Long et al., 2015; Moehlenkamp et al., 2018; Porter et al., 2018) and ingestion (and subsequent egestion) by zooplankton (e.g., Cole et al., 2013, 2016) offer an intriguing potential pathway for MP export out of the surface layer and in to the deep ocean and sediments, but to date no global estimate of the potential of marine aggregates (marine snow and fecal pellets) to transport MP has been made.

If marine snows and fecal pellets are a globally significant vector for microplastic removal from the surface ocean then it is concerning that primary and export production, particularly in the low latitudes, are projected to decline in the coming decades due to changes in climate (e.g., Kvale et al., 2015b; Laufkötter et al., 2015, 2016; Moore et al., 2018). At the same time, increases in the ocean plastic inventory are forecast (Jambeck et al., 2015; Koelmans et al., 2017; Isobe et al., 2019). Thus, the global ocean may be hit with a "double-whammy" of decreased plastics export potential and rapidly increasing plastics pollution in the coming decades. We present a first model-based estimation of the recent historical and future MP global surface export and sequestration potential of marine aggregates.

\section{METHODS}

For this study we use the University of Victoria Earth System Climate Model (UVic ESCM; Weaver et al., 2001; Eby et al., 2009; Keller et al., 2012). This particular version includes small phytoplankton and calcifiers (Kvale et al., 2015a), which were deactivated for the simulations as in Kvale et al. (2015b,
2018, 2019) to keep the model simple. The UVic ESCM used here therefore contains mixed phytoplankton and diazotroph phytoplankton categories, and a single zooplankton type. A seasonally-variable iron mask is applied (Keller et al., 2012).

Additional modifications were required in order to distinguish roles of zooplankton and phytoplankton export pathways on MP sequestration. Detritus in the UVic ESCM is formed by phytoplankton mortality, and zooplankton mortality, sloppy feeding and egestion. We assume MP aggregates in fecal pellets via zooplankton ingestion (Cole et al., 2016) and physically aggregates in marine snow (Moehlenkamp et al., 2018), though we do not explicitly trace MP, nor model marine particle aggregation. We introduce a new detritus tracer to divert $50 \%$ of zooplankton particulate losses into a detrital pool representing fecal pellets with an initial sinking rate of $18 \mathrm{~m} \mathrm{~d}^{-1}$ (double the initial sinking rate of the original detrital pool). We do this to calculate a separate detrital export pool (fecal pellets), with a faster sinking rate than the rest of the detritus. These new rates produce a decent fit to observed ocean nutrient profiles (Figure 1) and reflect the settling approximations of diatoms from Moehlenkamp et al. (2018) and copepod fecal pellets (Cole et al., 2016), where diatoms settle at approximately half the rate as pellets. What proportion of all zooplankton particulate losses is appropriate to represent egestion is un-constrained, therefore $50 \%$ is assumed. The remineralization rates of both detrital pools are the same, and unchanged from earlier versions of the model. Globally integrated NPP is now 53.04 Pg C per annum, lower than previous model versions (64.19 $\mathrm{Pg} \mathrm{C}^{-1}$, Kvale et al., 2015a) but still within the range reported (44-78 $\mathrm{Pg} \mathrm{C} \mathrm{y}^{-1}$; Carr et al., 2006; Jin et al., 2006; Buitenhuis et al., 2013). Primary production and grazing rates are shown in Figure 2.

The model was integrated at year 1800 boundary conditions (including agricultural greenhouse forcing and land ice) for more than 10,000 years until equilibration was achieved. From year 1800 to 1980 , historical $\mathrm{CO}_{2}$ forcing (Battle et al., 1996; Etheridge et al., 1996; MacFarling Meure et al., 2006), and geostrophically adjusted wind anomalies (Weaver et al., 2001) are applied as the control case. From 1980 to 2000 the model is forced with historical $\mathrm{CO}_{2}$ forcing, and a surface MP concentration mask in particles per square kilometer (Eriksen et al., 2014) is applied. This mask is scaled by change in atmospheric $\mathrm{CO}_{2}$ from the baseline at 2010, which was the (Eriksen et al., 2014) dataset year. Thus, the MP plastic concentration is at a minimum in year 1980 , and increases at the same rate as atmospheric $\mathrm{CO}_{2}$ into the future. The mask has no impact on particle export; it merely functions as a diagnostic tool for the export estimations. From 2000 to 2100 , the MP particle mask is applied and atmospheric $\mathrm{CO}_{2}$ follows business-as-usual RCP8.5 forcing (Riahi et al., 2007; Meinshausen et al., 2011). The choice to apply the MP mask from year 1980 is largely arbitrary, given how poorly historical and modern global MP distribution is known. It is known that plastics were present in the North Pacific and North Atlantic gyres at this time (Wong et al., 1974; Day and Shaw, 1987; Law et al., 2010). Figure 3 shows global MP inventory and atmospheric $\mathrm{CO}_{2}$ forcing.

Microplastic particle-to-mass conversions used two sourcesEriksen et al. (2014) and van Sebille et al. (2015), of which the latter produces significantly lighter plastic. 

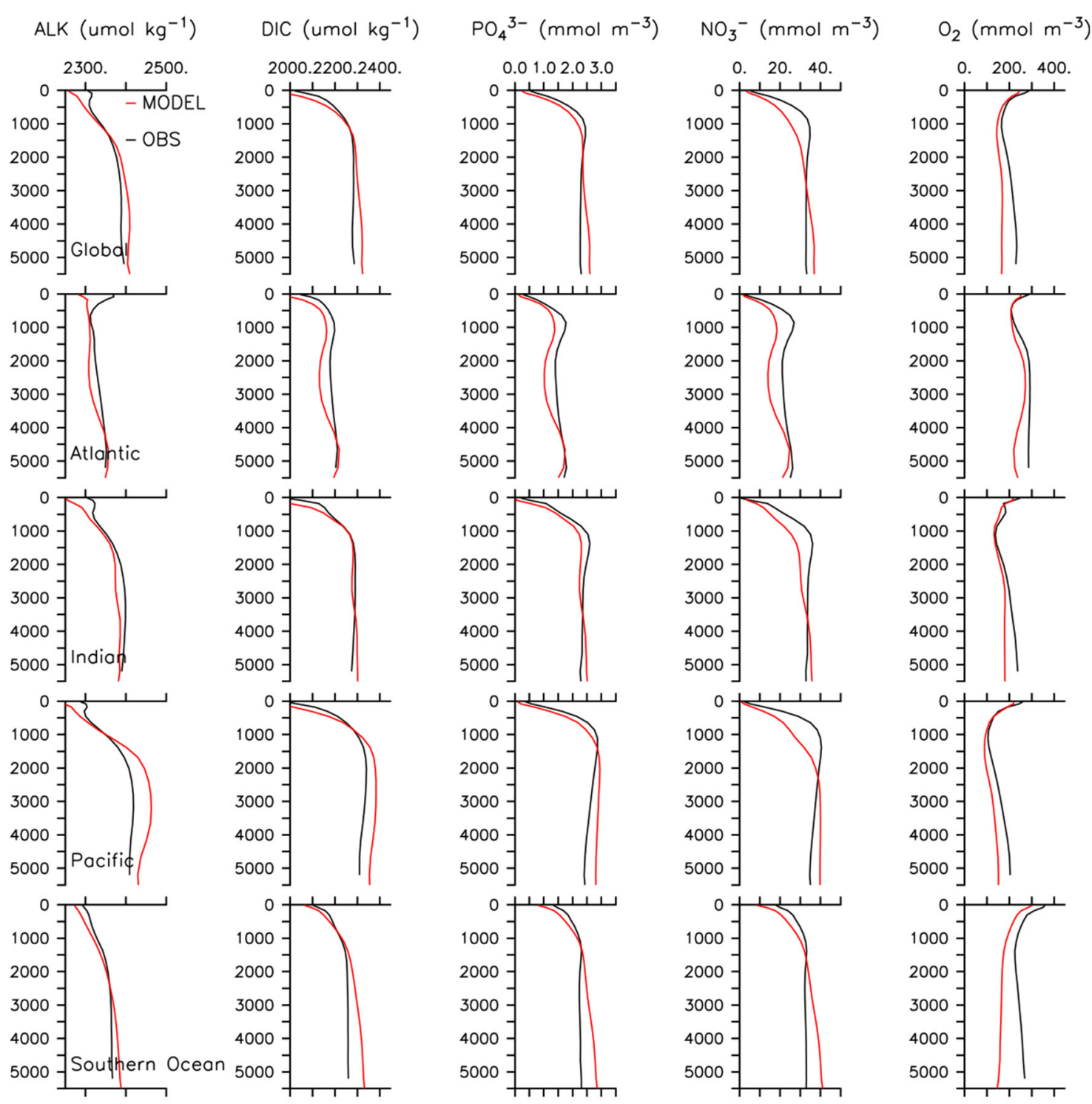

FIGURE 1 | Model global and basin-average profiles at year 2000 compared to WOA (Garcia et al., 2010a,b), and GLODAP (Key et al., 2004) data.

\section{DISCUSSION}

\subsection{Are Marine Aggregates a Plausible Vector of Surface Microplastic Removal?}

There were about $4.8 \mathrm{E} 12$ particles of MP in the surface ocean in 2010 (Eriksen et al., 2014). This figure is about 100 times too low given what is known about plastic pollution and breakdown (Eriksen et al., 2014). If these estimates are correct, a large-and as yet unconfirmed-sink of MP must operate in the ocean. In the following we investigate the potential role of marine aggregates (marine snow, and fecal pellets) as a sink.

A conservative estimate converts the annual average detrital export flux out of the surface layer in the UVic ESCM to a total number of marine snow and fecal pellet aggregates. Shanks and Trent (1980) estimated 3-5\% of total particulate organic carbon in the NE Atlantic and Monterrey Bay, California becomes aggregated. We take $3 \%$ as a global minimum, and conservatively convert $3 \%$ of modeled phytoplankton detrital surface export to mol $\mathrm{C} \mathrm{m}^{-3} \mathrm{~s}^{-1}$ exported as aggregated marine snow. If each aggregate contains between $1.27 \mathrm{mg}$ of carbon [an intermediate approximation from Shanks and Trent (1980)] and $8.8 \mathrm{mg}$ of carbon (if all aggregates have the characteristics of diatom aggregates, Simon et al., 1990), then a high and low value of the total number of aggregated marine snow in the surface ocean exported per year can be obtained. This is repeated for zooplankton egestion, which is traced separately. Zooplankton egestion is assigned a conversion factor of 1 pellet $=17 \mathrm{mg}$ carbon (Shatova et al., 2012) and 100\% of egested materials are pellets. In the UVic ESCM at year 2010, this produces a range of 3.4E17$2.3 \mathrm{E} 18$ (3.9E 18 at $5 \%$ flocculation rate) marine snow aggregates, 

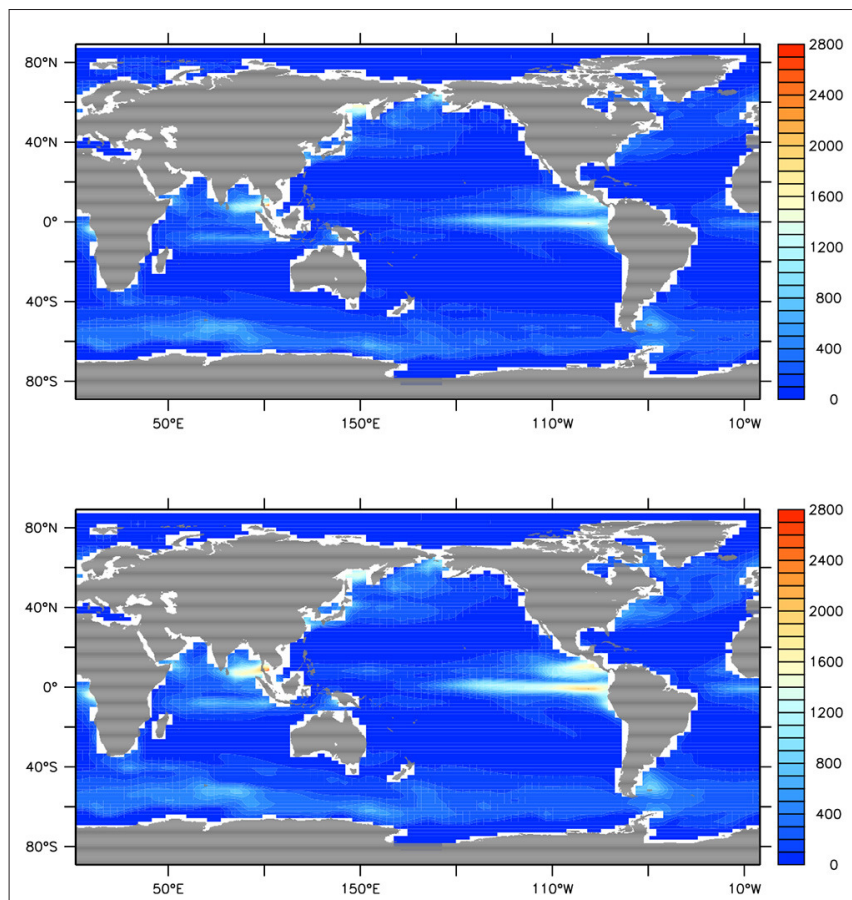

FIGURE 2 | Model year 2000 net primary production (Top) and zooplankton grazing rates (Bottom) in $\mathrm{g} \mathrm{C} \mathrm{y}^{-1}$. Values are integrated across depth and therefore values are larger for zooplankton grazing.

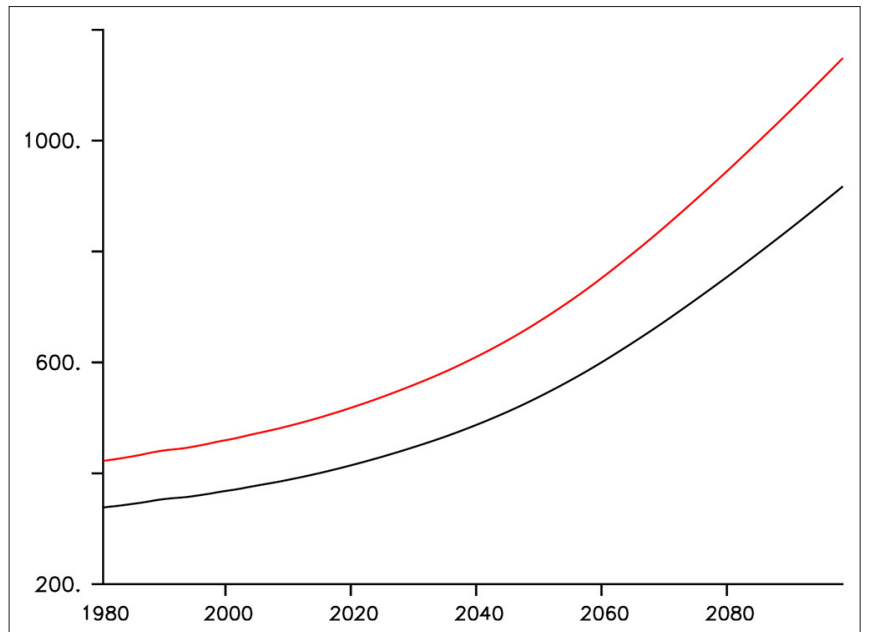

FIGURE 3 | Model atmospheric $\mathrm{CO}_{2}$ concentrations in ppm (black line) and MP inventory in particles $* 10^{10}$ (red line).

and 4.2E18 pellets exported per year from the surface ocean layer (top $50 \mathrm{~m}$ ). That is, there are 5 to 6 orders of magnitude more sinking biogenic particles in the surface ocean than MP particles. Even if it is assumed that one MP particle is transported by 1 organic marine snow aggregate or pellet, biological export can easily explain all of the missing MP. In ideal conditions, aggregates can hold 20 or more MP particles (see the photos in Cole et al., 2016; Moehlenkamp et al., 2018). In less ideal

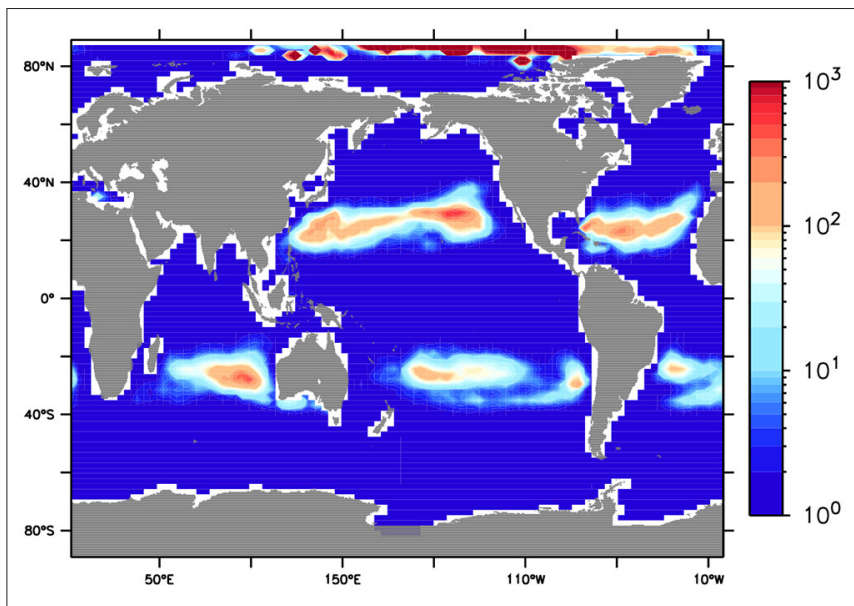

FIGURE 4 | Number of days from year 2010 it took for marine aggregate export at the seafloor to deposit an amount of MP equivalent to the surface concentration, if it is assumed $1 \mathrm{MP}$ particle is transported by 1 organic particle.

conditions, or in the real world, this ratio could be higher, or lower- the authors were not able to find other published, or unpublished, estimates. But why any MP would be found in the surface ocean at all, given the potential for marine snow and fecal pellets to remove it, suggests there are other factors that must be accounted for.

\subsection{Microplastic Surface Export Potential Is Not Removal}

Of course not all plastic will encounter biogenic particles, therefore the MP export potential must consider the spatial cooccurrence of MP and marine aggregates. Also, only a small fraction of organic detritus exported from the surface reaches the ocean floor, with the remainder remineralizing in the subsurface. If rates of marine aggregates reaching the seafloor replace surface export in the above calculation, and the result is scaled against MP surface concentration, the timescale of sequestration at the seafloor in 2010 was less than 2 years in the gyres (a maximum of 760 days in the North Pacific Gyre, Figure 4), assuming a $3 \%$ flocculation rate and diatom aggregate mass conversion. The model does not trace MP, so we make this calculation by dividing the surface MP concentration against the rate of organic aggregates reaching the seafloor, using the conversion and MP:aggregate assumptions mentioned above. Note the timescale of MP removal in the Arctic is the same order as the gyres, despite relatively low MP concentrations, because of the low annual average biological export rates. A 5\% flocculation rate and the Shanks and Trent (1980) aggregate carbon conversion rate would produce a maximum time to seafloor sequestration of 480 days in the gyres ( 1.3 years). These estimates are faster than the removal rate approximation of about 3 years from both Koelmans et al. (2017) and Isobe et al. (2019), who prescribed rates of removal not explicitly based on biology. These removal rates are reduced still further when considering that aggregates might transport multiple MP particles. However, our model does 
not resolve a biofouling/de-fouling cycle or other mechanisms, such as coprophagy, that might increase the timescale of removal to the seafloor.

The above analyses suggest marine snow and fecal pellets are an enormous and significant potential sink for MP in the surface ocean, with the applied assumptions. But, they are an ineffective sink in that only a small fraction of the potential removal results in permanent removal, otherwise there would exist no MP surface inventory. A biofouling/de-fouling cycle (used here to describe uptake and release by aggregation and remineralization, not biofilm fouling as described in Galloway et al., 2017), must be widespread and significant. The plastic exported from the surface by aggregates that does not reach the seafloor would be released via organic particle remineralization in the water column. Particle remineralization is a temperature-dependent process in our model. In 2010 in our model, about $75 \%$ of the MP could be expected to be de-fouled in the upper $500 \mathrm{~m}$ globally, but with geographical variability. MP exported out of the surface in the very high-MP concentration regions within the warm subtropical gyres could be expected to de-foul in the top $150 \mathrm{~m}$, which suggests an additional mechanism for rapid accumulation of surface MP in these regions: high rates of de-fouling and surface return driven by high rates of remineralization.

\subsection{The Missing Microplastic}

In 2010 there were about 3.4E4 tons of MP in the near-surface ocean, with the quantity of "missing" microplastic being 2 orders of magnitude greater (Eriksen et al., 2014). Our simulation allows us to calculate that the marine snow and pellet sink transported 2.3E5-6.6E5 tons of MP to the seafloor between 1980 and 2010, depending on conversion assumptions. This removal explains about $7-20 \%$ of the total missing microplastic. However, if it is assumed that each organic particle transports an average of 20 MP particles, this figure increases to 4.6E6-1.3E7 tons (139-393\% of the total missing MP, respectively).

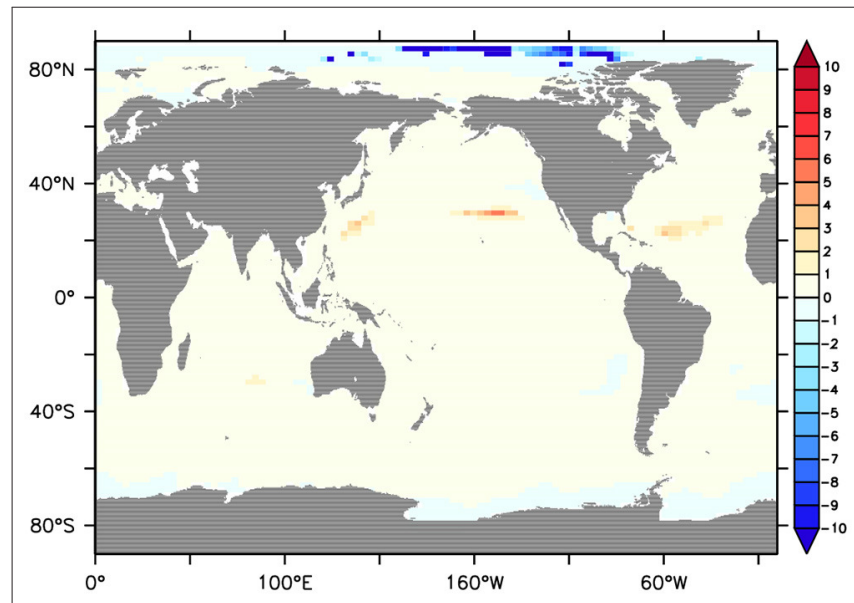

FIGURE 5 | Change in the number of years in 2100 (relative to 2010) it would take for marine aggregate export at the seafloor to deposit an amount of MP equivalent to the surface concentration, if it is assumed $1 \mathrm{MP}$ particle is transported by 1 organic particle.
Consider now that our methods scale model detrital export against the Eriksen et al. (2014) dataset, from which the "missing plastic" is already missing. This is a necessary assumption given the limitations of our earth system model, which does not resolve traceable plastic particles. The Eriksen et al. (2014) dataset is derived from a combination of langrangian modeling and surface sampling, biased toward known accumulation hotspots, such as the gyres. In the real world, it is expected that the majority of MP originating from coastlines would encounter organic aggregates well before reaching the gyres, and the fouling/de-fouling cycle would begin within a few days of the MP entering the ocean (Michels et al., 2018). Thus, the true estimate of MP removal by aggregates may be closer to $100 \%$ than $7 \%$, and the majority of affected MP particles may follow advection pathways different from the larger plastics; never reaching the gyres, and escaping the attention of scientists towing neuston nets.

\subsection{The Future of the Marine Aggregate Microplastic Sink}

Borrelle et al. (2017) observed a quasi-linear relationship between carbon emissions and plastic production since the early-2000s. If it is assumed that surface layer MP concentrations are also changing at the same rate as atmospheric $\mathrm{CO}_{2}$ concentrations, then the projected surface ocean MP inventory in the model is prescribed to increase at rates on the low end of projections by Koelmans et al. (2017) and Isobe et al. (2019). This prescribed MP concentration pathway is a highly oversimplified assumption, but unfortunately necessary given the lack of relevant data and mechanistic understanding of MP sinks. At the same time, global detrital export production is modeled to be $11 \%$ lower in 2100 , relative to year 2010 rates. Surprisingly, the model predicts only a $1 \%$ decline in MP removal by aggregates over this time frame. The discrepancy arises because the model prescribes a uniform increase in MP concentrations, keeping the spatial distribution the same as the Eriksen et al. (2014) dataset. Aggregate export

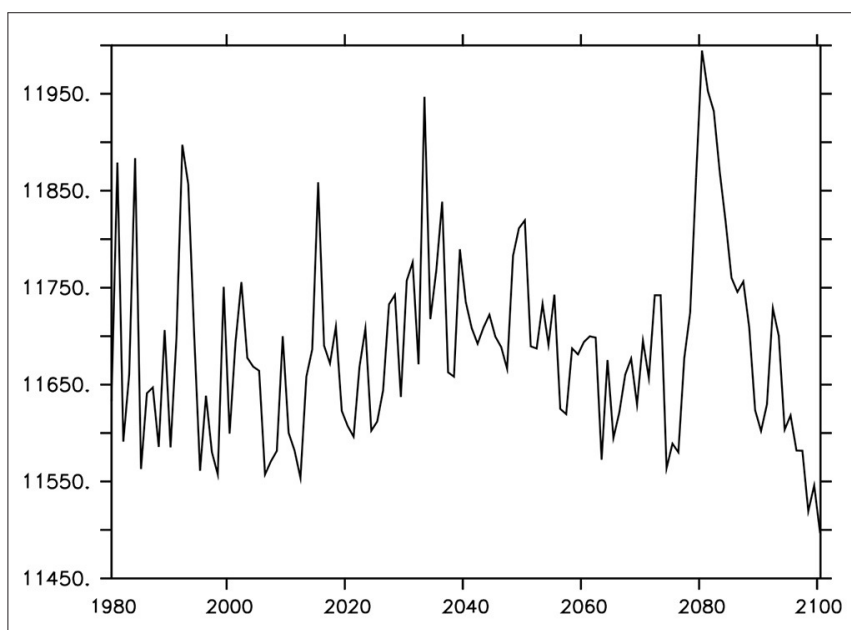

FIGURE 6 | Potential marine aggregate export of MP (in tons per year) to the seafloor, using a MP particle-to-mass conversion from Eriksen et al. (2014) and assuming $1 \mathrm{MP}$ particle is transported by 1 organic particle. 
changes very little in the gyres, with the largest low latitude decreases occurring in upwelling zones. At the same time, aggregate export rates in the Arctic and Southern Ocean increase enough that even though regional MP concentrations remain relatively low, the high removal rates mostly compensate for low latitude declines. The Arctic shows the higher sensitivity of the two poles, with decreases in time-to-removal of up to 10 years (Figure 5). The North Pacific subtropical gyre, on the other hand, shows an increase in the time-to-removal of about 5 years by 2100. This suggests that even though the global aggregate sink may change very little into the future, in the subtropical gyres it may become increasingly difficult to mitigate the MP pollution problem. Though, a more accurate projection of removal rates must include accounting for other forms of MP surface removal (e.g., photochemical degradation and physical breakdown, as well as microbial and aggregate fouling) that are not modeled here.

\section{CONCLUSIONS}

This study supports the hypothesis of a high potential of marine aggregates to remove MP from the ocean. This pathway, through marine snow and zooplankton fecal pellets, has been observed in controlled conditions, but not assessed at a global scale. Our estimates of annual MP sequestration at the seafloor by marine aggregates (Figure 6) represent about $0.06-8.8 \%$ of total annual ocean plastic pollution (Jambeck et al., 2015) and produce a removal timescale in the gyres shorter than other modeling efforts (Koelmans et al., 2017; Isobe et al., 2019). We theorize that MP exported by aggregates that does not reach the seafloor is released closer to the surface in the gyres, suggesting another mechanism for MP accumulation in these regions. In the future, the combined factors of increasing MP concentrations and decreasing detrital export production is calculated to have a small effect on the marine aggregate MP sink, because increased

\section{REFERENCES}

Battle, M., Bender, M., Sowers, T., Tans, P., Butler, J., Elkins, J., et al. (1996). Atmospheric gas concentrations over the past century measured in air from firn at the south pole. Nature 383, 231-235. doi: 10.1038/383231a0

Borrelle, S. B., Rochman, C. M., Liboiron, M., Bond, A. L., Lusher, A., Bradshaw, H., et al. (2017). Opinion: why we need an international agreement on marine plastic pollution. Proc. Natl. Acad. Sci. U.S.A. 114, 9994-9997. doi: 10.1073/pnas.1714450114

Buitenhuis, E. T., Hashioka, T., and Le Quéré, C. (2013). Combined constraints on global ocean primary production using observations and models. Glob. Biogeochem. Cycles 27, 847-858. doi: 10.1002/gbc.20074

Carr, M.-E., Friedrichs, M. A. M., Schmeltz, M., Aita, M. N., Antoine, D., Arrigo, K. R., et al. (2006). A comparison of global estimates of marine primary production from ocean color. Deep Sea Res. Part II Top. Stud. Oceanogr. 53, 741-770. doi: 10.1016/j.dsr2.2006.01.028

Choy, C. A., Robison, B. H., Gagne, T. O., Erwin, B., Firl, E., Halden, R. U., et al. (2019). The vertical distribution and biological transport of marine microplastics across the epipelagic and mesopelagic water column. Sci. Rep. 9:7843. doi: 10.1038/s41598-019-44117-2

Cole, M., Lindeque, P., Fileman, E., Halsband, C., Goodhead, R., Moger, J., et al. (2013). Microplastic ingestion by zooplankton. Environ. Sci. Technol. 47, 6646-6655. doi: 10.1021/es400663f export in the polar regions mostly offsets decreased export in the low latitudes. However, this analysis suggests globally significant fouling and defouling of MP, changes in which might also affect future trends in net MP removal.

The many assumptions made to produce our calculations were necessary given the lack of relevant data. This study is meant to serve as a first back-of-the-envelope estimate of the potential role of aggregates in sequestering MP in ocean sediments. We look forward to more detailed analyses in the coming years, and significant reductions in the calculation uncertainties, as more data become available.

\section{DATA AVAILABILITY STATEMENT}

The datasets analyzed for this study can be found in the https:// data.geomar.de/thredds/catalog/open_access/kvale_et_al_2019_ fmars/catalog.html.

\section{AUTHOR CONTRIBUTIONS}

KK conducted the model analysis and simulations, and wrote the manuscript. $\mathrm{KK}, \mathrm{AF}$, and $\mathrm{AO}$ contributed to the intellectual development of the material and manuscript revision.

\section{FUNDING}

This is a contribution to the Kiel research network Future Ocean. The authors gratefully acknowledge funding from GEOMAR.

\section{ACKNOWLEDGMENTS}

The authors gratefully acknowledge computing resources provided by Kiel University and GEOMAR Helmholtz Centre for Ocean Research, Kiel.
Cole, M., Lindeque, P. K., Fileman, E., Clark, J., Lewis, C., Halsband, C., et al. (2016). Microplastics alter the properties and sinking rates of zooplankton faecal pellets. Environ. Sci. Technol. 50, 3239-3246. doi: 10.1021/acs.est.5b05905

Cózar, A., Echevarría, F., González-Gordillo, J. I., Irigoien, X., Úbeda, B., Hernández-León, S., et al. (2014). Plastic debris in the open ocean. Proc. Natl. Acad. Sci. U.S.A. 111, 10239-10244. doi: 10.1073/pnas.1314 705111

Cózar, A., Martí, E., Duarte, C. M., García-de Lomas, J., van Sebille, E., Ballatore, T. J., et al. (2017). The arctic ocean as a dead end for floating plastics in the north atlantic branch of the thermohaline circulation. Sci. Adv. 3:e1600582. doi: 10.1126/sciadv.1600582

Day, R. H., and Shaw, D. G. (1987). Patterns in the abundance of pelagic plastic and tar in the north pacific ocean, 1976-1985. Mar. Pollut. Bull. 18(6 Suppl. B), 311-316. doi: 10.1016/S0025-326X(87)8 0017-6

Eby, M., Zickfeld, K., Montenegro, A., Archer, D., Meissner, K. J., and Weaver, A. J. (2009). Lifetime of anthropogenic climate change: millennial time scales of potential $\mathrm{CO}_{2}$ and surface temperature perturbations. J. Clim. 22, 2501-2511. doi: 10.1175/2008JCLI2554.1

Enders, K., Lenz, R., Stedmon, C. A., and Nielsen, T. G. (2015). Abundance, size and polymer composition of marine microplastics $=10 \mu \mathrm{m}$ in the atlantic ocean and their modelled vertical distribution. 
Mar. Pollut. Bull. 100, 70-81. doi: 10.1016/j.marpolbul.2015. 09.027

Eriksen, M., Lebreton, L. C. M., Carson, H. S., Thiel, M., Moore, C. J., Borerro, J. C., et al. (2014). Plastic pollution in the world's oceans: more than 5 trillion plastic pieces weighing over 250,000 tons afloat at sea. PLOS ONE 9:e111913. doi: 10.1371/journal.pone.01 11913

Etheridge, D., Steele, L., Langenfelds, R., Francey, R., Barnola, J., and Morgan, V. (1996). Natural and anthropogenic changes in atmospheric $\mathrm{CO}_{2}$ over the last 1000 years from air in antarctic ice and firn. J. Geophys. Res. Atmos. 101, 4115-4128. doi: 10.1029/95JD03410

Galloway, T. S., Cole, M., and Lewis, C. (2017). Interactions of microplastic debris throughout the marine ecosystem. Nat. Ecol. Evol. 1:116. doi: 10.1038/s41559-017-0116

Garcia, H., Locarnini, R. A., Boyer, T. P., Antonov, J., Baranova, O., Zweng, M. M., et al. (2010a). World Ocean Atlas 2009, Volume 3: Dissolved Oxygen, Apparent Oxygen Utilization, and Oxygen Saturation. Technical report, NOAA Atlas NESDIS 70, U.S. Government Printing Office, Washington, DC.

Garcia, H., Locarnini, R. A., Boyer, T. P., Antonov, J., Zweng, M. M., Baranova, O., et al. (2010b). World Ocean Atlas 2009, Volume 4: Nutrients (Phosphate, Nitrate, Silicate). Technical report, NOAA Atlas NESDIS 71, U.S. Government Printing Office, Washington, DC.

Hardesty, B. D., Harari, J., Isobe, A., Lebreton, L., Maximenko, N., Potemra, J., et al. (2017). Using numerical model simulations to improve the understanding of micro-plastic distribution and pathways in the marine environment. Front. Mar. Sci. 4:30. doi: 10.3389/fmars.2017. 00030

Isobe, A., Iwasaki, S., Uchida, K., and Tokai, T. (2019). Abundance of non-conservative microplastics in the upper ocean from 1957 to 2066. Nat. Commun. 10, 417. doi: 10.1038/s41467-019-0 $8316-9$

Isobe, A., Uchida, K., Tokai, T., and Iwasaki, S. (2015). East asian seas: a hot spot of pelagic microplastics. Mar. Pollut. Bull. 101, 618-623. doi: 10.1016/j.marpolbul.2015.10.042

Jambeck, J. R., Geyer, R., Wilcox, C., Siegler, T. R., Perryman, M., Andrady, A., et al. (2015). Plastic waste inputs from land into the ocean. Science 347, 768-771. doi: $10.1126 /$ science. 1260352

Jin, X., Gruber, N., Dunne, J. P., Sarmiento, J. L., and Armstrong, R. A. (2006). Diagnosing the contribution of phytoplankton functional groups to the production and export of particulate organic carbon, $\mathrm{CaCO} 3$, and opal from global nutrient and alkalinity distributions. Glob. Biogeochem. Cycles 20:GB2015. doi: 10.1029/2005GB002532

Keller, D. P., Oschlies, A., and Eby, M. (2012). A new marine ecosystem model for the University of Victoria Earth System Climate Model. Geosci. Model Dev. 5, 1195-1220. doi: 10.5194/gmd-5-1195-2012

Key, R., Kozyr, A., Sabine, C., Lee, K., Wanninkhof, R., Bullister, J., et al. (2004). A global ocean carbon climatology: results from global data analysis project (GLODAP). Glob. Biogeochem. Cycles 18:GB4031. doi: 10.1029/2004GB002247

Koelmans, A. A., Kooi, M., Law, K. L., and van Sebille, E. (2017). All is not lost: deriving a top-down mass budget of plastic at sea. Environ. Res. Lett. 12:114028. doi: 10.1088/1748-9326/aa9500

Kooi, M., Reisser, J., Slat, B., Ferrari, F. F., Schmid, M. S., Cunsolo, S., et al. (2016). The effect of particle properties on the depth profile of buoyant plastics in the ocean. Sci. Rep. 6:33882. doi: 10.1038/srep33882

Kvale, K., Turner, K. E., Keller, D. P., and Meissner, K. J. (2018). Asymmetric dynamical ocean responses in warming icehouse and cooling greenhouse climates. Environ. Res. Lett. 13:125011. doi: 10.1088/1748-9326/aaedc3

Kvale, K. F., Meissner, K. J., and Keller, D. P. (2015b). Potential increasing dominance of heterotrophy in the global ocean. Environ. Res. Lett. 10:074009. doi: 10.1088/1748-9326/10/7/074009

Kvale, K. F., Meissner, K. J., Keller, D. P., Schmittner, A., and Eby, M. (2015a). Explicit planktic calcifiers in the university of victoria earth system climate model, version 2.9. Atmos. Ocean 53, 332-350. doi: 10.1080/07055900.2015.10 49112

Kvale, K. F., Turner, K. E., Landolfi, A., and Meissner, K. J. (2019). Phytoplankton calcifiers control nitrate cycling and the pace of transition in warming icehouse and cooling greenhouse climates. Biogeosciences 16, 1019-1034. doi: 10.5194/bg-16-1019-2019
Laufkötter, C., Vogt, M., Gruber, N., Aita-Noguchi, M., Aumont, O., Bopp, L., et al. (2015). Drivers and uncertainties of future global marine primary production in marine ecosystem models. Biogeosciences 12, 6955-6984. doi: 10.5194/bg-12-6955-2015

Laufkötter, C., Vogt, M., Gruber, N., Aumont, O., Bopp, L., Doney, S. C., et al. (2016). Projected decreases in future marine export production: the role of the carbon flux through the upper ocean ecosystem. Biogeosciences 13, 4023-4047. doi: 10.5194/bg-13-4023-2016

Law, K. L., Morét-Ferguson, S., Maximenko, N. A., Proskurowski, G., Peacock, E. E., Hafner, J., et al. (2010). Plastic accumulation in the north atlantic subtropical gyre. Science 329, 1185-1188. doi: 10.1126/science.11 92321

Law, K. L., Morét-Ferguson, S. E., Goodwin, D. S., Zettler, E. R., DeForce, E., Kukulka, T., et al. (2014). Distribution of surface plastic debris in the Eastern Pacific Ocean from an 11-year data set. Environ. Sci. Technol. 48, 4732-4738. doi: $10.1021 /$ es 4053076

Long, M., Moriceau, B., Gallinari, M., Lambert, C., Huvet, A., Raffray, J., et al. (2015). Interactions between microplastics and phytoplankton aggregates: impact on their respective fates. Mar. Chem. 175, 39-46. doi: 10.1016/j.marchem.2015.04.003.

MacFarling Meure, C., Etheridge, D., Trudinger, C., Steele, P., Langenfelds, R., van Ommen, T., et al. (2006). Law dome $\mathrm{CO}_{2}, \mathrm{CH}_{4}$ and $\mathrm{N}_{2} \mathrm{O}$ ice core records extended to 2000 years bp. Geophys. Res. Lett. 33:L14810. doi: 10.1029/2006GL0 26152

Meinshausen, M., Smith, S. J., Calvin, K., Daniel, J. S., Kainuma, M. L. T., Lamarque, J.-F., et al. (2011). The RCP greenhouse gas concentrations and their extensions from 1765 to 2300. Clim. Change 109, 213-241. doi: 10.1007/s10584-011-0156-z

Michels, J., Stippkugel, A., Lenz, M., Wirtz, K., and Engel, A. (2018). Rapid aggregation of biofilm-covered microplastics with marine biogenic particles. Proc. R. Soc. B Biol. Sci. 285:20181203. doi: 10.1098/rspb.20 18.1203

Moehlenkamp, P., Purser, A., and Thomsen, L. (2018). Plastic microbeads from cosmetic products: an experimental study of their hydrodynamic behaviour, vertical transport and resuspension in phytoplankton and sediment aggregates. Elem. Sci. Anthropocene 6:61. doi: 10.1525/elementa.317

Moore, J. K., Fu, W., Primeau, F., Britten, G. L., Lindsay, K., Long, M., et al. (2018). Sustained climate warming drives declining marine biological productivity. Science 359, 1139-1143. doi: 10.1126/science.aao6379

Peng, X., Chen, M., Chen, S., Dasgupta, S., Xu, H., Ta, K., et al. (2018). Microplastics contaminate the deepest part of the world's ocean. Geochem. Perspect. Lett. 9, 1-5. doi: 10.7185/geochemlet.1829

Porter, A., Lyons, B. P., Galloway, T. S., and Lewis, C. (2018). Role of marine snows in microplastic fate and bioavailability. Environ. Sci. Technol. 52, 7111-7119. doi: 10.1021/acs.est.8b01000

Riahi, K., Gruebler, A., and Nakicenovic, N. (2007). Scenarios of long-term socio-economic and environmental development under climate stabilization. Technol. Forecast. Soc. Change 74, 887-935. doi: 10.1016/j.techfore.2006.05.026

Shanks, A., and Trent, J. (1980). Marine snow - sinking rates and potential role in vertical flux. Deep Sea Res. Part A Oceanogr. Res. Pap. 27, 137-143. doi: 10.1016/0198-0149(80)90092-8

Shatova, O., Koweek, D., Conte, M. H., and Weber, J. C. (2012). Contribution of zooplankton fecal pellets to deep ocean particle flux in the Sargasso Sea assessed using quantitative image analysis. J. Plankton Res. 34, 905-921. doi: $10.1093 /$ plankt/fbs053

Simon, M., Alldredge, A., and Azam, F. (1990). Bacterial carbon dynamics on marine snow. Mar. Ecol. Prog. Ser. 65, 205-211. doi: 10.3354/meps065205

Thompson, R. C., Olsen, Y., Mitchell, R. P., Davis, A., Rowland, S. J., John, A. W. G., et al. (2004). Lost at sea: where is all the plastic? Science 304, 838-838. doi: $10.1126 /$ science. 1094559

van Sebille, E., England, M. H., and Froyland, G. (2012). Origin, dynamics and evolution of ocean garbage patches from observed surface drifters. Environ. Res. Lett. 7:044040. doi: 10.1088/1748-9326/7/4/ 044040

van Sebille, E., Wilcox, C., Lebreton, L., Maximenko, N., Hardesty, B. D., van Franeker, J. A., et al. (2015). A global inventory of small floating plastic debris. Environ. Res. Lett. 10:124006. doi: 10.1088/1748-9326/10/12/ 124006 
Weaver, A., Eby, M., Wiebe, E., Bitz, C., Duffy, P., Ewen, T., et al. (2001). The uvic earth system climate model: model description, climatology, and applications to past, present and future climates. Atmos. Ocean 39, 361-428. doi: 10.1080/07055900.2001.9649686

Wong, C. S., Green, D. R., and Cretney, W. J. (1974). Quantitative tar and plastic waste distributions in the pacific Ocean. Nature 247, 30-32. doi: 10.1038/247030a0

Woodall, L. C., Sanchez-Vidal, A., Canals, M., Paterson, G. L., Coppock, R., Sleight, V., et al. (2014). The deep sea is a major sink for microplastic debris. R. Soc. Open Sci. 1:140317. doi: 10.1098/rsos. 140317
Conflict of Interest: The authors declare that the research was conducted in the absence of any commercial or financial relationships that could be construed as a potential conflict of interest.

Copyright $(2020$ Kvale, Friederike Prowe and Oschlies. This is an open-access article distributed under the terms of the Creative Commons Attribution License (CC BY). The use, distribution or reproduction in other forums is permitted, provided the original author(s) and the copyright owner(s) are credited and that the original publication in this journal is cited, in accordance with accepted academic practice. No use, distribution or reproduction is permitted which does not comply with these terms. 